
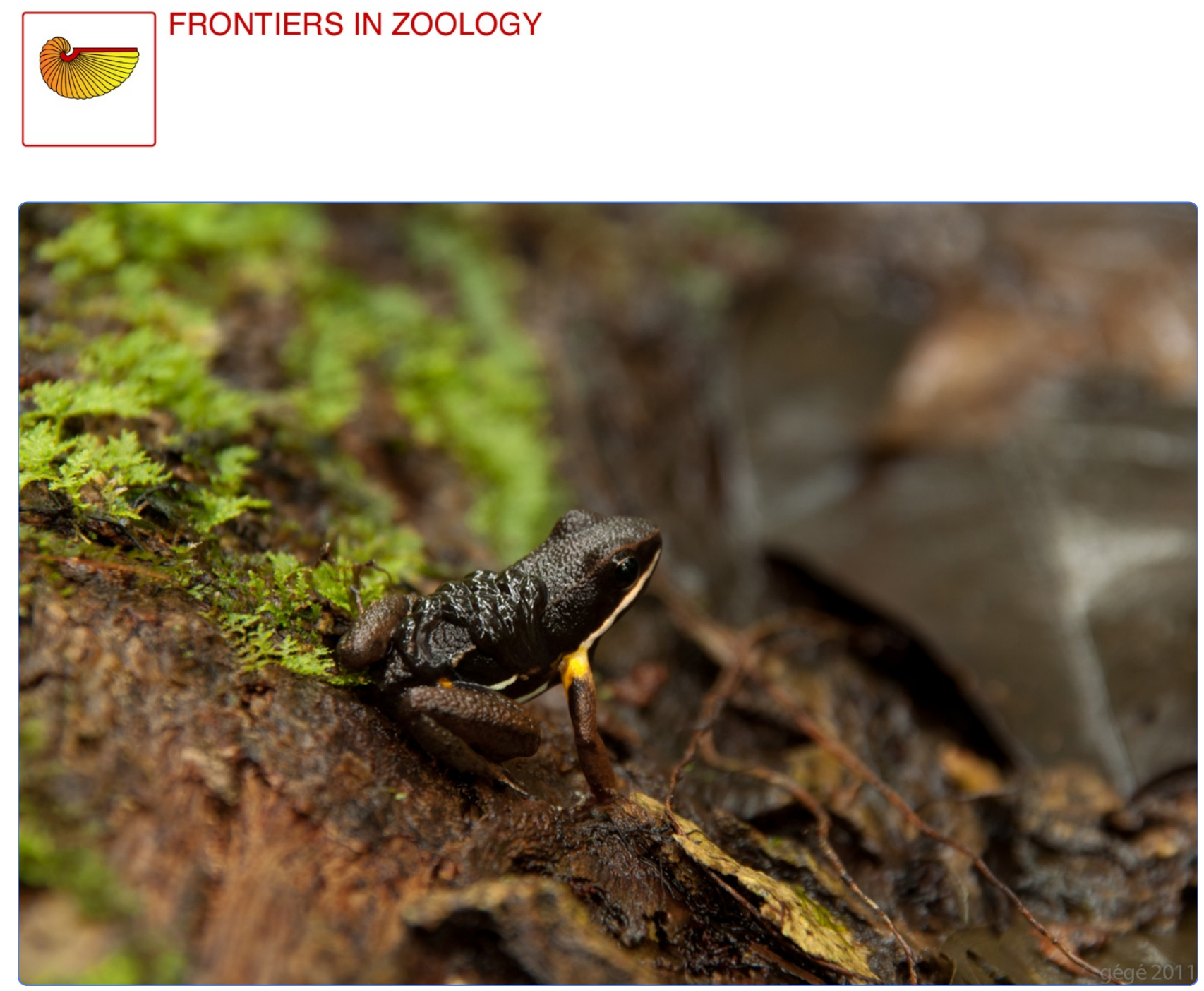

Tadpole transport logistics in a Neotropical poison frog: indications for strategic planning and adaptive plasticity in anuran parental care

Ringler et al. 


\title{
Tadpole transport logistics in a Neotropical poison frog: indications for strategic planning and adaptive plasticity in anuran parental care
}

Eva Ringler ${ }^{1,2^{*}}$, Andrius Pašukonis ${ }^{2}$, Walter Hödl ${ }^{1}$ and Max Ringler ${ }^{1,3}$

\begin{abstract}
Introduction: Individuals should aim to adjust their parental behaviours in order to maximize the success of their offspring but minimize associated costs. Plasticity in parental care is well documented from various bird, mammal and fish species, whereas amphibians were traditionally assumed as being highly instinct-bound. Therefore, little is known about 'higher' cognitive abilities of amphibians, such as strategic planning and behavioural flexibility. Dendrobatid frogs have evolved a remarkable diversity of parental behaviours. The most noticeable of these behaviours is tadpole transport, which is obligatory in almost all species. Nonetheless, there is limited knowledge about spatial and temporal patterns of tadpole transport and the possible existence of behavioural plasticity on the individual level. In this study, we investigated correlates of tadpole transport behaviour in a natural population of the dendrobatid frog Allobates femoralis during five years.

Results: Tadpole transport was predominantly observed during morning hours. Although tadpoles were carried almost exclusively by males $(N=119)$, we also observed ten females performing this task. The parentage analysis revealed that in all cases females transported their own offspring. In contrast, four tadpole-carrying males were not the genetic fathers of the larvae they were transporting. The average clutch size of 20 eggs and our observation of an average of 8 tadpoles on the back of transporting individuals indicate that frogs do not carry entire clutches at once, and/or that they distribute their larvae across several water bodies. Contrary to the predictions from a hypothetical random search for deposition sites, the number of transported tadpoles was higher in males that travelled over longer distances.

Conclusions: Our results suggest a strong selective pressure on males to shift the time invested in tadpole transport to periods of low intra-specific competition. The number of tadpoles on the back of the males significantly correlated with displacement distance from the respective home territories, indicating a strategic non-random tadpole transport rather than random search for suitable tadpole deposition sites during tadpole transport. The observation of females who occasionally transported larvae supports the prevalence of adaptive plasticity in parental behaviours even in a species with a rather low level of parental care.
\end{abstract}

Keywords: Dendrobatidae, Allobates femoralis, Natural population, Parental care, Spatial behaviour, Larval transport

\footnotetext{
* Correspondence: eva.ringler@univie.ac.at

${ }^{1}$ Department of Integrative Zoology, University of Vienna, Althanstrasse 14,

A-1090 Vienna, Austria

${ }^{2}$ Department of Cognitive Biology, University of Vienna, Althanstrasse 14,

A-1090 Vienna, Austria

Full list of author information is available at the end of the article
}

\section{Biomed Central}

(c) 2013 Ringler et al.; licensee BioMed Central Ltd. This is an Open Access article distributed under the terms of the Creative Commons Attribution License (http://creativecommons.org/licenses/by/2.0), which permits unrestricted use, distribution, and reproduction in any medium, provided the original work is properly cited. The Creative Commons Public Domain Dedication waiver (http://creativecommons.org/publicdomain/zero/1.0/) applies to the data made available in this article, unless otherwise stated. 


\section{Introduction}

Costs and benefits of parental care play a major role in the evolution of parental behaviours and have been investigated in detail across various animal taxa (for reviews see $[1,2])$. Parental care is assumed to evolve only in situations where the benefits of care exceed the associated costs [3]. While benefits are mainly derived from an increased survival of offspring, the costs often remain obscure and are difficult to measure. Costs of parental care to the caregiving individual include direct costs, such as an increased predation risk and higher energetic expenditure, as well as indirect costs, such as missed mating opportunities [1,4]; for amphibians see [5]. In many animal species, the certainty of parentage for the caregiving individual/sex has a significant impact on the parental effort provided (likelihood of being the 'true' parent; [4,6-10] but see [11]). According to the associated costs and benefits of care, individuals should aim to adjust their parental behaviours in order to maximize the success of their offspring while minimizing the associated costs [12]. These adjustments can either be longterm behavioural changes associated with 'learning' or changes in the nervous system as a result of experience (i.e. developmental behavioural plasticity). They can also involve immediate responses to changing conditions (i.e. activational behavioural plasticity; [13]). Activational behavioural plasticity therefore encompasses short-term effects, where the behavioural response is not affected by past environmental conditions but solely by the current situation. In this manuscript we mainly focus on activational behavioural plasticity in our study species.

Amphibians were traditionally assumed to be highly instinct-bound, if not simple 'reflex machines' (cf. [14]). Over the last decades, and as a result of many behavioural and neurophysiological studies, this view has slightly changed [15]. Still, little is known about 'higher' cognitive abilities of amphibians, such as strategic planning and behavioural flexibility. Amphibians are particularly interesting for studying the evolution of parental care because all forms (male, female, or bi-parental care) can be found across this taxon. In amphibians, parental care is relatively most common in salamanders and newts, although parental behaviour in these two groups is mainly restricted to the attendance of eggs and larvae [16-18]. Anuran amphibians generally do not provide any care after oviposition. Nonetheless, many frog families have independently evolved at least some form of parental care $[16,17,19]$. Interestingly, $92 \%$ of all anuran species that exhibit parental care deposit their eggs outside of water [17]. The transition towards terrestrial eggs probably promoted the evolution of various strategies to enhance and ensure larval development, given that anuran larvae in general, even those of species with terrestrial eggs, are aquatic and require water to complete metamorphosis [5]. The main adaptations in this context are either direct development of tadpoles inside the clutch $[20,21]$, or parental care for eggs and/or tadpoles $[16,17,20]$. Parental behaviour can protect the terrestrial eggs from desiccation, pathogens, and predators, and can ensure the development of aquatic larvae until metamorphosis. It may include egg guarding, attendance and provisioning of larvae, transport of eggs, and transport of larvae (reviewed in [5]). In cases where tadpoles must be transported to water, parental care is even obligate for offspring survival. In situations where tadpole deposition sites are not commonly available inside parental territories, the transport of aquatic larvae over larger distances might impose considerable time and energy investments on the transporting parent (but see [22]). Particularly the combination of territoriality and terrestrial egg deposition might have played an important role in the evolution of parental care in frogs. In aquatically breeding species, multiple paternities in single clutches are quite common. This is due to multiple males amplexing single females and due to competing stray sperm from males in neighbouring matings [23]. In terrestrially breeding species, oviposition commonly takes place inside the territories of individuals. This should result in a high certainty of parentage for both males and females [24]. Such a high certainty, in turn, might have led to generally higher parental investment in territorial species.

Poison frogs (Dendrobatidae) show a remarkable diversity in their parental behaviour [25-33]. Male tadpole transport without any previous and/or further provisioning and attendance is assumed to be the ancestral form of parental care in dendrobatid frogs [27,29], but exclusive female- and bi-parental care have evolved in several species (see [34,35]). Most dendrobatids carry their larvae from terrestrial egg deposition sites to water bodies such as small streams, swamps, temporary ponds, or to phytotelmata in leaf axils, bromeliads, or tree holes [5,31]. In some species, larvae even complete their entire development while being carried on the parent's back [36,37]. For several dendrobatid species, recent research has demonstrated the presence of behavioural plasticity in deposition strategies according to predator presence (visual cues: [38], chemical cues [39]), phytotelm quality [40], seasonal variation in desiccation risk [41], and presence of conspecific tadpoles [42]). We hypothesize that further specific behavioural adaptations have evolved in this taxon to minimize the associated costs of tadpole transport, such as energy investment, predation risk, or lost mating opportunities. All other things being equal, larger individuals should be able to take up more tadpoles at once than smaller ones. They either provide more space for tadpoles to hold on or are physically stronger. If the main costs of tadpole transport arise from indirect negative effects associated with transporting distance, especially time and 
energy expenditure, then we would expect transporting individuals to take up as many tadpoles as possible, preferably all at once. They may then either deposit all the tadpoles in the first water body they encounter, or distribute them successively over several water bodies along their route as they search for suitable water bodies. These behaviours would either yield no identifiable effect or a negative correlation between the number of tadpoles on the back of transporting individuals and the distance covered. Given that tadpoles are not immediately released when the parent jumps into water, males might be able to influence the actual number of tadpoles released by the duration they spend in the water pool and also by the number of wiping movements of the hind limbs (E. Ringler pers. obs.).

In the present study we used the anuran model species Allobates femoralis, a small diurnal poison frog (Dendrobatidae), which is distributed throughout Amazonia [43], to investigate correlates of tadpole transport behaviour. During the reproductive season, which coincides with the local rainy season [44,45], males call from elevated structures on the forest floor to announce territory possession to male competitors and to attract females [46]. Pair formation, courtship, and mating take place in the male's territory $[47,48]$. Here, externally fertilized clutches of approximately 20 eggs are laid in the leaf litter $[49,50]$. Both sexes are highly iteroparous and polygamous within prolonged reproductive periods [51]. Females can produce one clutch every eight days on average [49], and males were observed to attend up to five clutches at the same time [51]. Tadpole transport takes place after 15-20 days of larval development and is mainly performed after heavy rains by males [28]. Nonetheless, occasional cases of transporting females have been documented $[49,52-54]$. Tadpoles are usually deposited in rather large water bodies ranging from medium-sized temporal pools to floodplains $[55,56]$, as well as peccary wallows and footprints [57]. Small terrestrial phytotelmata such as palm fronds and holes in fallen trees are also used when available (pers. obs. by all authors). Studies from captivity have shown that $A$. femoralis distribute their tadpoles across several water pools, if available, with tadpoles requiring 40-50 days until metamorphosis [49].

In this study, we investigated correlates of tadpole transport behaviour in a natural population of the dendrobatid frog A. femoralis during five consecutive breeding seasons. This involved analysing physical properties and spatial behaviour of all individuals in the study population and using molecular parentage analyses to verify parent-offspring relationships.

\section{Results}

During the whole study period from 2008 to 2012, we recorded 1373 individual adult $A$. femoralis $\left(N_{\mathrm{m}} / N_{\mathrm{f}} ; 2008\right.$ : 144/60, 2009: 160/71, 2010: 203/97, 2011: 247/107, 2012:
192/92) in the study area. The survival rates of adult frogs were relatively low: year-to-year recapture rates averaged $14 \%$ for males and $15 \%$ for females, corroborating previous findings in this and another A. femoralis population (cf. $[51,56,58])$.

We observed a total of 129 tadpole transport events (2008: $N=14,2009: N=18,2010: N=32,2011: N=31$, 2012: $N=34$ ). In the vast majority of cases, males performed this task (92.2\%, 119 out of 129). However, we also observed 10 females with larvae on their back (7.8\%). Twelve individuals, all of them males, were observed twice during tadpole transport: 4 males in two successive years, and 8 males within the same year. The number of tadpoles carried by individual frogs ranged from 1 to 25 (median \pm iqr $=8 \pm 2, N=129$ ). The number of tadpoles transported by single frogs did not differ significantly between the sexes (males: median \pm iqr $=8 \pm 2$, range $=1-25, \quad N=106 ;$ females: $\operatorname{median} \pm \mathrm{iqr}=9 \pm 2$, range $=1-17, N=10$; Mann - Whitney test, $U=523.5$, $P=0.949$ ).

Tadpole transport occurred mainly during morning hours (median \pm iqr $=11: 13 \pm 10: 30$, range 8:43-18:35, Figure 1). The time of observations did not differ significantly between males and females (Mann-Whitney test, $U=594, P=0.424)$.

In the parentage analysis, COLONY always assigned both tested tadpoles from a single transporting event to an identical parent pair. For 115 tadpole-pairs (96.6\% out of 119), paternity was assigned to the male carrier, while for four pairs paternity was assigned to either a direct neighbour $(N=3$; for a definition of direct neighbour see [50]) or an unidentified male $(N=1)$. For the ten tadpole pairs transported by females, maternity was in all cases assigned to the female carrier. During tadpole transport, males were encountered on average $27.52 \pm 30.90 \mathrm{~m}$

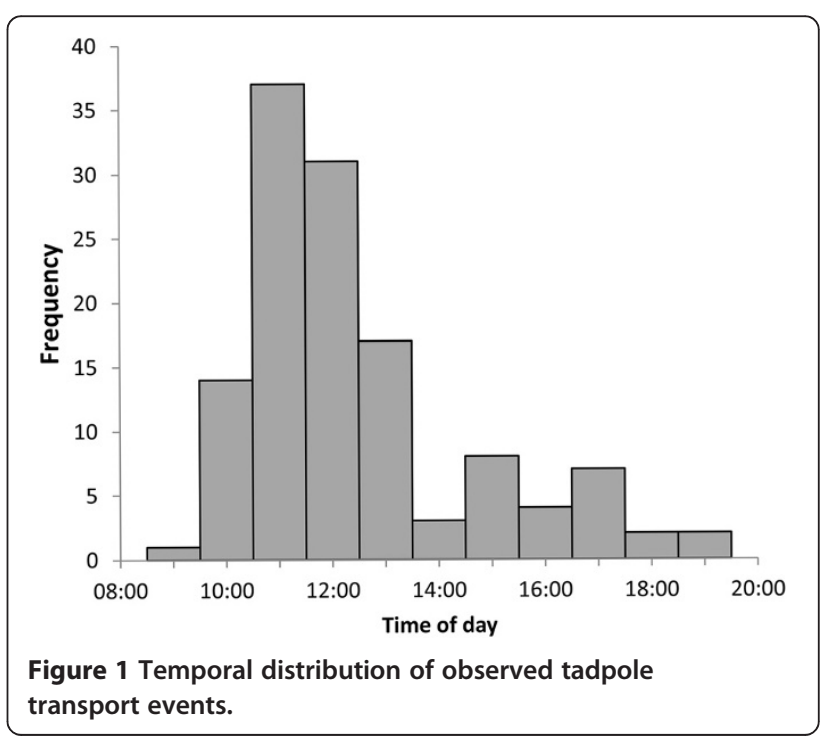


(median \pm iqr) away from their home territories (range $=$ $1.64-185.14 \mathrm{~m})$.

The multiple correlation analysis identified a significant correlation between 'age' and snout urostyle length 'SUL' (Spearman, $\rho=0.306, P=0.003, N=95$; Table 1). Accordingly, 'age' was omitted in the subsequent analysis, given that SUL offers the higher explanatory power.

The stepwise linear regression model revealed that only displacement distance significantly predicted the number of tadpoles on a male's back $(t=2.575, P=0.012)$ (Table 2 , Figure 2), but not time of day $(t=-0.622, P=0.536)$ or SUL $(t=1.101, P=0.274)$.

\section{Discussion}

The present study underlines the existence of adaptive plasticity in parental behaviour in amphibians by comprehensively analysing the tadpole transport behaviour in A. femoralis during five years. Our data contribute to knowledge on tadpole transport behaviour in other dendrobatid species and improve our understanding of the evolution of male/female parental care in poison frogs.

The average displacement distance of $A$. femoralis males from their home territories was $27 \mathrm{~m}$, which is about double the diameter of their average territories (13.9 m, cf. [59]). One transporting male travelled almost $185 \mathrm{~m}$ (straight line distance) and even crossed a small creek. This indicates that suitable water bodies for larval deposition are not easily found within the territories of all males, potentially constituting a limiting resource in our study population. Tadpole transport was mainly observed during morning hours (Figure 1). We attribute this to several factors. On the one hand, the maximum calling activity in A. femoralis takes place in the afternoon in our

Table 1 Multiple Correlation Analysis of the variables 'age', 'time of day', 'SUL', and 'displacement distance' ('dist_log')

\begin{tabular}{|c|c|c|c|c|c|}
\hline & & Dist_log & Age & Time & $\overline{\text { SUL }}$ \\
\hline & $\rho$ & & -0.196 & 0.158 & 0.192 \\
\hline \multirow[t]{3}{*}{ Dist_log } & Sign. (two tailed) & & 0.081 & 0.140 & 0.082 \\
\hline & $N$ & & 80 & 89 & \\
\hline & $\rho$ & -0.196 & & -0.137 & 0.306 \\
\hline \multirow[t]{3}{*}{ Age } & Sign. (two tailed) & 0.081 & & 0.173 & 0.003 \\
\hline & $N$ & 80 & & 100 & \\
\hline & $\rho$ & 0.158 & -0.137 & & -0.08 \\
\hline \multirow[t]{3}{*}{ Time } & Sign. (two tailed) & 0.140 & 0.173 & & 0.39 \\
\hline & $N$ & 89 & 100 & & \\
\hline & $\rho$ & 0.192 & 0.306 & -0.084 & \\
\hline \multirow[t]{2}{*}{ SUL } & Sign. (two tailed) & 0.082 & 0.003 & 0.395 & \\
\hline & $N$ & 83 & 95 & 104 & \\
\hline
\end{tabular}

$\rho$ (Spearman correlation coefficient), $P$ (significance, two tailed), $N$ (number of tested cases), significant correlations are given in bold.
Table 2 Output table of the stepwise multiple linear regression analysis

\begin{tabular}{cccc}
\hline Predictor & $\boldsymbol{\beta}$ & $\boldsymbol{t}$ & $\boldsymbol{p}$ \\
\hline Distance & 3.810 & 2.575 & 0.012 \\
Time of day & -0.067 & -0.622 & 0.536 \\
SUL & 0.119 & 1.101 & 0.274
\end{tabular}

We found a significant correlation only for the parameters 'number of tadpoles' and 'displacement distance', but not for 'time of day' and 'SUL'. Model statistics: $\mathrm{R}^{2}=0.076, \mathrm{~F}(1,81)=6.63, p=0.012$.

study population (3 to 6 p.m., pers. obs. by all authors) and elsewhere [45]. Thus, males that carry their tadpoles in the morning will typically have returned to their home territories by afternoon (cf. [60]), minimizing the risk of losing mating opportunities. Particularly if distances to suitable aquatic sites are far, we expect a strong selective advantage for males that shift tadpole transport to times with low or no conspecific calling activity. On the other hand, temperature is slightly lower during morning hours, potentially causing less energy expenditure than afternoon transporting (cf. [61]). Finally, tadpole transport in the morning provides males with more daylight hours to return to their home territory.

Previous studies have already mentioned that $A$. femoralis females occasionally transport tadpoles [49,52-54]. However, concise data on the frequency of this behaviour under natural conditions were lacking. In our study almost $8 \%$ of all transporting events were performed by females. The parentage analysis revealed that all these females carried their own offspring. Females typically choose their mates within $20 \mathrm{~m}$ of their perching sites and return to their resting sites immediately after oviposition $[47,50,56]$. It is therefore very unlikely that females 'accidentally' end up with tadpoles on their back unless they actively return to the oviposition site, sit on the clutch, and wait until the tadpoles climb on her

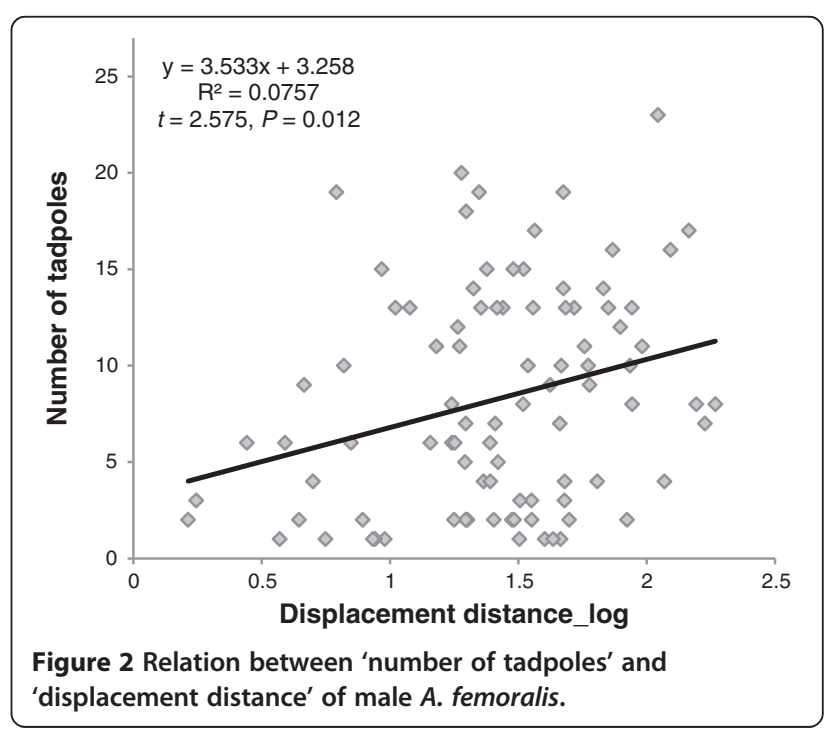


back, which takes about $30 \mathrm{~min}$ (E. Ringler pers. obs. in males). Nonetheless, during the five-year study we never observed females returning to their previously laid clutches when males were still present. Consequently, we see no indication that female transporting behaviour could be an infrequently expressed error reflecting similar male/female nervous and endocrine systems (cf. [62]). The question remains how such behaviour could become adaptive; i.e. how benefits exceed costs. We hypothesize that the costs of tadpole transport might be less for females than for males. Females do not defend territories and thus do not risk losing a territory during their absence. Furthermore, under optimal conditions, they can produce a clutch every eight days [49]. Oviposition is not restricted to a limited time frame and is often triggered by specific reproductive stimuli (cf. [63]). Accordingly, we assume that tadpole transport would not severely restrict mating opportunities. Energy expenditure and predation risk are presumably the same for males and females. At the same time, females could ensure further survival of a clutch in which they have already invested substantial time and energy (and that already survived over two weeks). We therefore also hypothesise that, due to the low tadpole transport costs, females might gain substantial fitness benefits by flexibly taking over parental duties if the male is absent. In other taxa, behavioural flexibility with respect to parental care has generally been studied in bi-parental species. When both parents are involved in brood care, males and females often cooperate by exhibiting different parental roles [64]. Such sex-specific parental behaviours, however, might change when one of the parents disappears. Manipulation experiments in fish and birds have shown that widowed parents were capable of raising the offspring alone by either increasing the own parental effort or even switching between parental roles $[65,66]$. These experiments suggest that the coordination of roles displayed in bi-parental species is flexible and may depend on the presence and the behaviour of the other parent. Little attention has been paid to such flexibility in uni-parental species, i.e. the takeover of parental duties in the generally non-caring sex. Behavioural plasticity of tadpole deposition behaviour has been documented for some dendrobatid species in several contexts [38-42]. These frogs integrate multiple factors such as water quality, presence of predators, con- or heterospecific tadpoles, and pool size and adapt their behaviour accordingly [33]. Further studies are needed to reveal reasons for and mechanisms of female tadpole transport in A. femoralis.

Surprisingly, not all transporting males were identified as the genetic fathers of the carried larvae. Three males carried the larvae of immediate neighbours (i.e. calling males of adjacent territories), one the larvae of an unidentified individual (i.e. the genotype of the putative father as inferred by COLONY was not found amongst our paternal candidates). In the former three males, we assume that territory shifts and/or territory overlaps might have occurred. Such shifts and overlaps are rare during the breeding season (cf. [56,59]), but they might occur due to changes in forest floor structure (e.g. fallen branches or trees) or interactions amongst competing males. In the one case where no suitable father could be identified, we speculate that the actual father died or abandoned his territory prior to our study period and that another male had taken over his territory. Another possibility would be that the clutch was sired by a sneaking male (cf. [67]), although we never directly observed any active sneaking behaviour during our five-year study ([51], pers. observations of all authors), or found indirect evidence through genetic parentage inferences of larvae from clutches [50]. We assume that successful siring of clutches by sneaking males is largely precluded by the elaborate courtship behaviour and because mating takes place in vigorously defended territories $[56,68]$.

Perhaps there is a fixed behavioural pattern in A. femoralis males to carry all encountered clutches inside their territory to water sites without distinguishing between own or foreign offspring. Although such behaviour would facilitate the evolution of sneaking behaviour, we have no indications that sneaking is a frequent alternative mating strategy in this species. Further experimental studies are needed to reveal if a fixed action pattern is involved and whether it is exclusively elicited in males that simultaneously have own clutches inside their territories.

Adult frogs carried an average 8 larvae on their back. In a Brazilian $A$. femoralis population, frogs carried all tadpoles from single clutches at once [48]. In A. femoralis, clutches average about 20 eggs and larval mortality inside the clutch is low $[49,50]$. The low average number of carried tadpoles in our study indicates that these frogs distribute their larvae across several water bodies and probably do not transport entire clutches at once to single pools.

The distances covered by A. femoralis males were considerably longer than those reported for any other dendrobatid frog (Dendrobates pumilio: max. $20 \mathrm{~m}$, I. Meuche and H. Pröhl pers. comm.; Ranitomeya ventrimaculata: within a circle with a maximum diameter of $8.5 \mathrm{~m}$, approximated from the area of the maximum 95\% home range kernel, [69]). Given our sampling regime of registering all frogs at chance encounter locations along their transportation route, the maximum transporting distances must be considered low estimates. Surprisingly, the distance of males to their home territories during tadpole transport correlated significantly positively with the number of tadpoles on their back. No correlation was found between tadpole number and SUL or time of day. The high variance of data points in the correlation between 'number of tadpoles' and 'displacement distance' (Figure 2) 
is probably because individual frogs were caught at chance locations along their transport route. We therefore hypothesize that the number of tadpoles taken up at once is influenced by the distance of the territory to suitable water bodies (cf. [49]). This implies a detailed spatial knowledge of the surrounding area along with some sort of strategic planning rather than random searching. Given that deposition sites are not abundant and unevenly distributed in our study area, knowledge about pool locations would significantly reduce effort and risks of tadpole transport. While in Dendrobates auratus males regularly explore their surroundings for potential deposition sites [70], A. femoralis males generally do not leave their home territories during the reproductive season [56]. However, they might have collected spatial information during the onset of the rainy season before territories become established, or during previous tadpole transport events. A recent study revealed a high homing performance of male A. femoralis after experimental translocations [71]. Translocated males successfully returned to their territories from up to $400 \mathrm{~m}$ and showed a very high homing success for distances up to $200 \mathrm{~m}$, suggesting that this ability is restricted to an area of potential familiarity.

Several direct and indirect costs of tadpole transport have been proposed (reviewed in [5]). Predation risk might increase if larval transportation reduces movement ability (but see [72]). We lack information on whether this is the case in A. femoralis. Furthermore, if foraging is reduced or absent while transporting larvae, frogs might significantly lose weight, posing severe health risks or disadvantages in subsequent male-male competitions. Durations of tadpole transport in dendrobatid species are highly variable (see table 11.3, p. 524-526 in [5]). Some species release the tadpoles within a few hours (D. pumilio, [30]), while in others the larvae remain on the back for several days (e.g. Colostethus inguinalis, [26]). A. femoralis is an opportunistic feeder, suitable food is quite abundant and tadpole transport generally takes only a few hours [60] - male A. femoralis were even observed to feed during acoustic playback experiments under experimental conditions [73]. We therefore do not assume any severe weight loss during tadpole transport in this species. Further costs include the invested time and energy. We observed individual frogs to carry up to 25 tadpoles, corresponding to about $28 \%$ of their own body weight $\left(\right.$ mean $_{\text {tadpole }}=$ $0.0192 \mathrm{~g}, N=3$; mean $_{\text {males }}=1.7 \mathrm{~g}, N=121$, unpubl. data). The energy expenditure in tadpole-transporting frogs is no doubt higher than unencumbered movement, but has not been investigated in any dendrobatid species so far. The factor 'time investment' could also impact individual fitness. For example, mating opportunities might be lost due to the absence from home territories or resting sites. Particularly in cases of strong male-male competition for territories, there may be strong selective pressure against male tadpole transport, given the high risk of losing the territory while absent (cf. [74]). Nevertheless, in dendrobatid frogs, male-only care is quite widespread and is assumed to be the ancestral state of parental care in the whole family $[27,29]$. We suppose that these indirect costs in $A$. femoralis males are minimized because tadpole transport mainly occurs during morning hours, when less intra-specific competition for territories or courtship takes place. Nonetheless, possible negative effects of high mating success and subsequent increased parental effort in A. femoralis males (cf. $[75,76])$ remain to be investigated.

\section{Conclusions}

The present study investigates the tadpole transport behaviour in a Neotropical frog with male territoriality and paternal care. Tadpoles were transported mainly during morning hours, indicating a selective pressure on males to shift the invested time towards periods of low intraspecific competition. The number of carried tadpoles significantly correlated with displacement distance from the respective home territories. This suggests strategic non-random transport rather than random search for suitable deposition sites in A. femoralis males. Females occasionally transported their own offspring, supporting an adaptive plasticity in parental behaviours, even in a species with a low level of parental care. These observations combined indicate strategic planning and behavioural flexibility in our study species, two poorly known behavioural phenomena in anuran amphibians.

\section{Methods}

\section{Study population}

We conducted our study in a lowland rainforest near the field camp 'Saut Pararé' $\left(4^{\circ} 02^{\prime}\right.$ N, $52^{\circ} 41^{\prime}$ W) in the nature reserve 'Les Nouragues', French Guiana, in a natural population of $A$. femoralis. The study plot was approximately $180 \mathrm{~m} \times 450 \mathrm{~m}$ in size and naturally delimited by a river and two streams (for more details see [51]). Sampling took place during the reproductive period of A. femoralis in the years 2008 to 2012 (28 January until 24 April 2008, 17 January until 16 March 2009, 16 January until 16 March 2010, 30 January until 24 February 2011, and 27 January until 5 April 2012). We conducted daily surveys from about $0900 \mathrm{~h}$ to $1900 \mathrm{~h}$. By continuously sampling all individuals encountered during the surveys, we attempted total sampling of all male and females in the study plot and to record as many individuals as possible in all years. All frogs were identified based on digital photographs of their distinct ventral patterns and sexed by the presence (males) or absence (female) of vocal sac folds. We recorded the precise spatial locations of all frogs in the field on a digital map with the mobile GIS software $\operatorname{ArcPad}^{\mathrm{Tm}} 7 / 8 / 10$ (ESRI), using pocket computers (Hewlett Packard $\mathrm{PPaq}^{\mathrm{mm}}$ hx1950 \& 
hx4700, Ashtech MobileMapper ${ }^{\mathrm{Tm}}$ 6) and further handled the data in ArcGIS ${ }^{\text {ma }} 9.3$ (ESRI). We determined body size of all adults (SUL, snout urostyle length) from dorsal photographs in front of a reference scale using the software Image J 1.47 [77]. If individuals were encountered during tadpole transport, we recorded the number of tadpoles on the back, and two tadpoles were taken and preserved in $96 \%$ ethanol. All sampling was conducted in strict accordance with current French and EU law and followed the current ASAB guidelines for the treatment of animals in behavioural research and teaching. Detailed descriptions of the sampling procedures for tissue material of adult individuals are given in [51,58].

\section{Genotyping and parentage analysis}

Genomic DNA was isolated using a Proteinase K digestion followed by a standard phenol-chloroform protocol. PCR amplification of seven polymorphic microsatellite loci, genotyping and checking of genotyping errors followed the procedures described in [51]. Genotypes of adults from 2008 and 2009 were already available from a previous study [51]. To identify the parents of the tadpoles sampled in the present study, we used an identical approach. All parentage assignments were performed with the software COLONY v.2 [78]. Each tadpole was tested 'naïvely' without prior information about assumed full sib relationships (for tadpoles taken from the same transporting adult) or about assumed parents (i.e. the transporting individual).

\section{Analyses of tadpole transport activity}

We included information of all tadpole transport events recorded over the study period. Consecutive tadpole transport events of the same male (female) were assumed to be independent when the respective larvae were assigned to different mothers (fathers) or when the two successive observations were separated by more than 2 days. If individuals were observed twice within one transporting event, we only included the data of the first encounter in our analyses.

For each observed transporting event, we recorded the parameters 'displacement distance', 'SUL', 'age' and 'time of day'. The parameter 'displacement distance' could be assessed only for male tadpole transport events because only in males do the location of their clutch and their own permanent location (i.e. their territory) correspond over lengthier periods. Accordingly, we determined the centroid point of all encounter locations of a given male, assuming that all transporting males had been territorial; reproductive success in A. femoralis is significantly associated with male territoriality [51]. We excluded all encounters during tadpole transport from the determination of male territories. Then we calculated the straight line distance of the centroid points to the respective encounter locations during tadpole transport. Males exclusively observed during transport were excluded from the analysis. When an apparent territory change occurred within one sampling period, we included only the territory that was temporarily closest to the respective transport event to calculate transporting distance. For the subsequent multiple stepwise regression analysis, we log-transformed the transport distances because the number of tadpoles transported is limited by clutch size and cannot increase indefinitely with transporting distance. For the parameter 'age', we differentiated between 'new' (all frogs that were first encountered in the respective year of sampling) and 'old' individuals (frogs already encountered in previous years). We did not include individuals from the first year (2008) because survivors from previous years could not be identified. 'Time of day' corresponds to the exact time of the respective tadpole transport event, converted into minute of the day (i.e. 12:00 a.m. $=720 \mathrm{~min}$ ).

Prior to the stepwise multiple regression analysis to test possible predictors of the number of transported tadpoles, we performed a multiple correlation analysis to identify possible co-linearity of the tested variables. Finally, we performed a stepwise linear regression analysis with 'displacement distance' and 'SUL' as potential predictors of the number of tadpoles transported. To exclude a possible sampling bias in respect to the time of day when individual frogs were caught, we also included 'time of day' in the analysis. In cases where multiple transportation events were observed for single males within one or between successive years, we included only the first transport event per male in order to avoid pseudo-replication.

In the course of a concurrent study on the influence of reproductive resource supplementation on population size, we installed artificial water pools in the study area in March 2009 (Ringler et al., submitted). In order to test whether data points from 2008-2009 and 2010-1012 could be pooled despite altering resource availability, we performed an ANCOVA for all tested correlations to identify potential differences in pre- and post-treatment tadpole transportation behaviour. There was no significant difference in the relation number of tadpoles 'tp' and all tested variables before and after the installation of the artificial pools (tp_ distance: $F_{23,68}=0.005, P=0.946$; tp_SUL: $F_{21,84}=0.733$, $P=0.394$; tp_time: $\left.F_{27,86}=0.698, P=0.405\right)$. We therefore pooled all data points in the subsequent analyses.

All statistical analyses were performed in IBM SPSS statistics 20.0.0. Normality of the data was tested with the Kolmogorov-Smirnov $Z$ test, and in cases where variables significantly deviated from a normal distribution, non-parametric tests (Mann-Whitney $U$ test, SpearmansRank-Correlation) were applied.

\section{Competing interests}

The authors declared that they have no competing interests. 


\section{Authors' contributions}

ER and MR designed the study. All authors participated in the field work. ER performed all molecular and statistical analyses and drafted the manuscript. AP, WH and MR provided valuable comments on the manuscript. All authors read and approved the final manuscript.

\section{Acknowledgements}

Our study was approved by the scientific committee of the research station where fieldwork was conducted (http://www.nouragues.cnrs.fr/F-conseil. html). All necessary permissions for toe clipping and sampling of larvae were provided by the 'Centre National de la Recherche Scientifique' (CNRS, Permit Number: 12/05/2009) and by the 'Direction Régionale de l'Environment de Guyane' (DIREN, Permit Number: arrêté n\%/2010-015). Work in the lab was supported by the Austrian Science Fund (FWF): P24788-B22 (PI Eva Ringler, http://www.fwf.ac.at) and the Nouragues Grant 2009 \& 2010 (PI Max Ringler). Eva Ringler was supported by a DOC-fFORTE scholarship and a L'ORÉAL Austria fellowship 'For Women in Science' from the Austrian Academy of Sciences. Andrius Pašukonis was supported by a PhD scholarship from the Austrian Science Fund (FWF): W1234-G17 (PI: Thomas Bugnyar). Thanks to Julia Felling, Jasmin Primus, Anna Rausch, Magdalena Erich, and the students of the field courses (University of Vienna) in 2009, 2010, and 2012 for assistance in the field. We are grateful to Norbert Milasowszky and Bruno Gingras for statistical advice.

\section{Author details}

'Department of Integrative Zoology, University of Vienna, Althanstrasse 14, A-1090 Vienna, Austria. ${ }^{2}$ Department of Cognitive Biology, University of Vienna, Althanstrasse 14, A-1090 Vienna, Austria. ${ }^{3}$ Department of Tropical Ecology and Animal Biodiversity, University of Vienna, Rennweg 14, A-1030 Vienna, Austria.

Received: 7 September 2013 Accepted: 6 November 2013 Published: 9 November 2013

\section{References}

1. Clutton-Brock TH: The evolution of parental care. Princeton, NJ: Princeton Univ. Pr; 1991.

2. Gross MR: The evolution of parental care. Q Rev Biol 2005, 80:37-45.

3. Alonso-Alvarez C, Velado A: Benefits and costs of parental care. In The evolution of parental care. Edited by Royle NJ, Smiseth PT, Kölliker M. Oxford, United Kingdom: Oxford University Press; 2012:40-61.

4. Trivers RL: Parental investment and sexual selection. In Sexual selection and the descent of man. Edited by Campbell B. Chicago: Aldine; 1972:136-179.

5. Wells KD: The ecology and behavior of amphibians. Chicago: The University of Chicago Press; 2007

6. Møller AP, Birkhead TR: Certainty of paternity covaries with paternal care in birds. Behav Ecol Sociobiol 1993, 33:261-268

7. Owens IP: When kids just aren't worth it: cuckoldry and parental care. Trends Ecol Evol 1993, 8:269-271.

8. Westneat DF, Sherman PW: Parentage and the evolution of parental behavior. Behav Ecol 1993, 4:66-77.

9. Neff BD, Gross MR: Dynamic adjustment of parental care in response to perceived paternity. Proc R Soc Lond B 2001, 268:1559-1565.

10. Neff BD: Decisions about parental care in response to perceived paternity. Nature 2003, 422:716-719.

11. Sheldon BC: Relating paternity to paternal care. Philos T Roy Soc B 2002 , 357:341-350.

12. Winkler DW: A general model for parental care. Am Nat 1987, 130:526-543.

13. Snell-Rood EC: An overview of the evolutionary causes and consequences of behavioural plasticity. Anim Beh 2013, 85:1004-1011.

14. Tinbergen N: The study of instinct. Oxford: Oxford Univ. Pr; 1953.

15. Dicke U, Roth G: Evolution of the Amphibian Nervous System. In Evolutionary Neuroscience. Edited by Kaas JH. Oxford: Academic Press; 2009:169-232.

16. Crump ML: Parental Care. In Social behaviour. Edited by Sullivan BK Heatwole H. Chipping Norton, UK: Surrey Beatty; 1995:518-567.

17. Crump ML: Parental care among the Amphibia. In Advances in the Study of Behavior: Parental Care: Evolution, Mechanisms, and Adaptive Significance. Edited by Rosenblatt JS, Snowdon CT. San Diego: Academic Press; 1996:109-144
18. Nussbaum RA: Parental care. In Reproductive biology and phylogeny of Urodela. Edited by Sever DM. Enfield, NH: Science Publishers; 2003:527-612.

19. McDiarmid RW: Evolution of parental care in frogs. In The development of behavior: comparatice and evolutionary aspects. Edited by Burghardt GM, Bekoff M. New York: Garland STPM Press; 1978:127-147.

20. Hödl W: Reproductive diversity in Amazonian lowland frogs. In Biology and physiology of amphibians. Edited by Stuttgart HW. New York: Fischer; 1990:41-60.

21. Bahir MM, Meegaskumbura M, Manamendra-Arachchi K, Schneider CJ, Pethiyagoda R: Reproduction and terrestrial direct development in Sri Lankan shrub frogs (Ranidae: Rhacophorinae: Philautus). Raffles Bull Zool 2005, 12:339-350.

22. Jowers MJ, Downie JR: Tadpole deposition behaviour in male stream frogs Mannophryne trinitatis (Anura: Dendrobatidae). J Nat Hist 2005, 39:3013-3027.

23. Roberts JD, Byrne PG: Polyandry, sperm competition, and the evolution of anuran amphibians. In Advances in the Study of Behavior. Edited by Brockmann HJ, Roper TJ, Naguib M, Mitani JC, Simmons W. Burlington: Elsevier; 2011:1-53.

24. Waldman B: Kin recognition in amphibians. In Kin recognition. Edited by Hepper PG. Cambridge: Cambridge Univ. Pr; 1991:162-219.

25. Wells KD: Behavioral ecology and social organization of a dendrobatid frog (Colostethus inguinalis). Behav Ecol Sociobiol 1980, 6:199-209.

26. Wells KD: Evidence for growth of tadpoles during parental transport in Colostethus inguinalis. J Herpetol 1980, 14:428-430.

27. Weygoldt P: Evolution of parental care in dart poison frogs (Amphibia: Anura: Dendrobatidae). Z Zool Syst Evolutionsforsch 1987, 25:51-67.

28. Aichinger M: Tadpole transport in relation to rainfall, fecundity, and body size in five species of poison-dart frogs from Amazonian Peru. Amphibia-Reptilia 1991, 12:49-55.

29. Summers K, Weigt LA, Boag PT, Bermingham E: The evolution of female parental care in poison frogs of the genus Dendrobates: evidence from mitochondrial DNA sequences. Herpetologica 1999, 55:254-270.

30. Pröhl $H$, Berke $O$ : Spatial distributions of male and female strawberry poison frogs and their relation to female reproductive resources. Oecologia 2001, 129:534-542.

31. Lötters S, Jungfer K, Henkel FW, Schmidt W: Poison frogs. Biology, species \& captive husbandry. Frankfurt am Main: Edition Chimaira; 2007.

32. Brown $J$, Morales $V$, Summers $K$ : Home range size and location in relation to reproductive resources in poison frogs (Dendrobatidae): a Monte Carlo approach using GIS data. Anim Behav 2009, 77:547-554.

33. Brown J: The evolution of parental care, aposematism and color diversity in Neotropical poison frogs. Evol Ecol 2013, 27:825-829.

34. Clough M, Summers K: Phylogenetic systematics and biogeography of the poison frogs: evidence from mitochondrial DNA sequences. Biol $\rfloor$ Linn Soc 2000, 70:515-540.

35. Brown JL, Morales $V$, Summers $K$ : A key ecological trait drove the evolution of biparental care and monogamy in an amphibian. Am Nat 2010, 175:436-446.

36. Lescure J: Las larvas de dendrobatidae. Reunión Iberoamericana de Conservacion y Zoologia de Vertebrados 1984, Actas II:37-45.

37. Kaiser $H$, Altig R: The atypical tadpole of the dendrobatid frog Colostethus chalcopis, from Martinique, French Antilles. J Herpetol 1994, 28:374-378.

38. McKeon CS, Summers K: Predator driven reproductive behavior in a tropical frog. Evol Ecol 2013, 27:725-737.

39. Schulte LM, Yeager J, Schulte R, Veith M, Werner P, Beck LA, Lötters S: The smell of success: choice of larval rearing sites by means of chemical cues in a Peruvian poison frog. Anim Behav 2011, 81:1147-1154.

40. Poelman EH, Wijngaarden RAP, Raaijmakers CE: Amazon poison frogs (Ranitomeya amazonica) use different phytotelm characteristics to determine their suitability for egg and tadpole deposition. Evol Ecol 2013, 27:661-674.

41. Schulte LM, Lötters S: The power of the seasons: rainfall triggers parental care in poison frogs. Evol Ecol 2013, 27:711-723.

42. Poelman EH, Dicke M: Offering offspring as food to cannibals: oviposition strategies of Amazonian poison frogs (Dendrobates ventrimaculatus). Evol Ecol 2007, 21:215-227.

43. Amézquita A, Lima AP, Jehle R, Castellanos L, Ramos Ó, Crawford AJ, Gasser H, Hödl W: Calls, colours, shape, and genes: a multi-trait approach to the study of geographic variation in the Amazonian frog Allobates femoralis. Biol J Linn Soc 2009, 98:826-838. 
44. Gottsberger B, Gruber E: Temporal partitioning of reproductive activity in a neotropical anuran community. J Trop Ecol 2004, 20:271-280.

45. Kaefer IL, Montanarin A, da Costa Rosangela S, Lima AP: Temporal patterns of reproductive activity and site attachment of the brilliant-thighed frog Allobates femoralis from central Amazonia. J Herpetol 2012, 46:549-554.

46. Hödl W, Amézquita A, Narins PM: The role of call frequency and the auditory papillae in phonotactic behavior in male dart-poison frogs Epipedobates femoralis (Dendrobatidae). J Comp Physiol A 2004, 190:823-829.

47. Roithmair ME: Field studies on reproductive behaviour in two dart-poison frog species (Epipedobates femoralis, Epipedobates trivittatus) in Amazonian Peru. Herpetol J 1994, 4:77-85.

48. Montanarin A, Kaefer IL, Lima AP: Courtship and mating behaviour of the brilliant-thighed frog Allobates femoralis from Central Amazonia: implications for the study of a species complex. Ethol Ecol Evol 2011 23:141-150.

49. Weygoldt P: Zur Fortpflanzungsbiologie von Phyllobates femoralis (Boulenger) im Terrarium. Salamandra 1980, 16:215-226.

50. Ringler $E$, Ringler $M$, Jehle $R$, Hödl $W$ : The female perspective of mating in A. femoralis, a territorial frog with paternal care - a spatial and genetic analysis. PLOS ONE 2012, 7:e40237.

51. Ursprung $E$, Ringler M, Jehle R, Hödl W: Strong male/male competition allows for nonchoosy females: high levels of polygynandry in a territorial frog with paternal care. Mol Ecol 2011, 20:1759-1771.

52. Crump ML: Reproductive strategies in a tropical anuran community. Lawrence: University of Kansas Printing Service; 1974

53. Silverstone PA: A revision of the poison-arrow frogs of the genus Phyllobates Bibron in Sagra (Family Dendrobatidae). L A Nat Hist Mus Sci Bull 1976, 27:1-53.

54. Caldwell JP, de Araújo MC: Amphibian faunas of two eastern Amazonian rainforest sites in Pará, Brazil. Occasional Papers Sam Noble Oklahoma Museum of Natural History 2005, 16:1-41.

55. Gascon C: Breeding-habitat use by five Amazonian frogs at forest edge. Biodiv Cons 1993, 2:438-444.

56. Ringler M, Ursprung E, Hödl W: Site fidelity and patterns of short- and long-term movement in the brilliant-thighed poison frog Allobates femoralis (Aromobatidae). Behav Ecol Sociobiol 2009, 63:1281-1293.

57. Beck H, Thebpanya P, Filiaggi M: Do neotropical peccary species (Tayassuidae) function as ecosystem engineers for anurans. J Trop Ecol 2010, 26:407-414.

58. Ursprung $E$, Ringler $M$, Jehle $R$, Hödl W: Toe regeneration in the neotropical frog Allobates femoralis. Herpetol J 2011, 21:83-86.

59. Ringler M, Ringler E, Magaña Mendoza D, Hödl W: Intrusion experiments to measure territory size: development of the method, tests through simulations, and application in the frog Allobates femoralis. PLOS ONE 2011, 6:e25844.

60. Roithmair ME: Territoriality and male mating success in the dart-poison frog, Epipedobates femoralis (Dendrobatidae, Anura). Ethology 1992, 92:331-343.

61. Navas CA, Gomes FR, Carvalho JE: Thermal relationships and exercise physiology in anuran amphibians: integration and evolutionary implications. Comp Biochem Physiol A 2008, 151:344-362.

62. Wingfield JC: Hormone-behavior interaction and mating systems in male and female birds. In The Differences Between the Sexes. Edited by Short RV, Balaban E. Cambridge: Cambridge Univ. Press; 1994:303-330.

63. Scarliata JK, Murphy CG: Timing of oviposition by female barking treefrogs (Hyla gratiosa). J Herpetol 2003, 37:580-582.

64. Balshine S: Patterns of parental care in vertebrates. In The evolution of parental care. Edited by Royle NJ, Smiseth PT, Kölliker M. Oxford: Oxford Univ. Press; 2013:62-80.

65. Itzkowitz M, Santangelo N, Richter M: Parental division of labor and the shift from minimal to maximal role specializations: an examination using a biparental fish. Anim Behav 2001, 61:1237-1245.

66. Storey $A E$, Bradbury $C G$, Joyce $T L$ : Nest attendance in male meadow voles: the role of the female in regulating male interactions with pups. Anim Behav 1994, 47:1037-1046.

67. Meuche I, Pröhl H: Alternative mating tactics in the strawberry poison frog (Oophaga pumilio). Herpetol J 2011, 21:275-277.

68. Narins PM, Hödl W, Grabul DS: Bimodal signal requisite for agonistic behavior in a dart-poison frog, Epipedobates femoralis. Proc Natl Acad SC US A 2003, 100:577-580.

69. Poelman EH, Dicke M: Space use of Amazonian poison frogs: testing the reproductive resource defense hypothesis. J Herpetol 2008, 42:270-278.
70. Summers K: Sexual selection and intra-female competition in the green poison-dart frog, Dendrobates auratus. Anim Behav 1989, 37:797-805.

71. Pašukonis $A$, Ringler $M$, Brandl $H B$, Mangione R, Ringler $E$, Hödl W: The homing frog: high homing performance in a territorial dendrobatid frog Allobates femoralis (Dendrobatidae). Ethology 2013, 119:762-768.

72. Downie JR, Robinson E, Linklater-McLennan RJ, Somerville E, Kamenos N: Are there costs to extended larval transport in the Trinidadian stream frog, Mannophryne trinitatis (Dendrobatidae). J Nat Hist 2005, 39:2023-2034.

73. Ursprung $E$, Ringler $M$, Hödl W: Phonotactic approach pattern in the neotropical frog Allobates femoralis: a spatial and temporal analysis. Behaviour 2009, 146:153-170.

74. Townsend DS: The costs of male parental care and its evolution in a neotropical frog. Behav Ecol Sociobiol 1986, 19:187-195.

75. Summers K: Paternal care and the cost of polygyny in the green dart-poison frog. Behav Ecol Sociobiol 1990, 27:307-313.

76. Summers K, Earn DJD: The cost of polygyny and the evolution of female care in poison frogs. Biol J Linn Soc 1999, 66:515-538.

77. Rasband WS: ImageJ. Bethesda, Maryland, USA: U. S. National Institutes of Health; 1997-2011.

78. Wang J: A new method for estimating effective population sizes from a single sample of multilocus genotypes. Mol Ecol 2009, 18:2148-2164.

doi:10.1186/1742-9994-10-67

Cite this article as: Ringler et al:: Tadpole transport logistics in a

Neotropical poison frog: indications for strategic planning and adaptive plasticity in anuran parental care. Frontiers in Zoology 2013 10:67.

\section{Submit your next manuscript to BioMed Central and take full advantage of:}

- Convenient online submission

- Thorough peer review

- No space constraints or color figure charges

- Immediate publication on acceptance

- Inclusion in PubMed, CAS, Scopus and Google Scholar

- Research which is freely available for redistribution 